Cite this: Phys. Chem. Chem. Phys. 2014, 16, 16030

Received 5th March 2014, Accepted 15th May 2014

DOI: $10.1039 / \mathrm{c} 4 \mathrm{cp} 00951 \mathrm{~g}$

www.rsc.org/pccp

\section{Impedance analysis of secondary phases in a Co-implanted ZnO single crystal}

\author{
M. Younas, ${ }^{* a b}$ L. L. Zou, ${ }^{a}$ M. Nadeem, ${ }^{b}$ Naeem-ur-Rehman, ${ }^{a c}$ S. C. Su, ${ }^{a}$ Z. L. Wang, ${ }^{a}$ \\ W. Anwand, ${ }^{d}$ A. Wagner, ${ }^{d}$ J. H. Hao, ${ }^{e}$ C. W. Leung, ${ }^{e}$ R. Lortz and F. C. C. Ling*a
}

Co ions with $100 \mathrm{keV}$ energy with a fluence of $1 \times 10^{15} \mathrm{~cm}^{-2}$ are implanted into $\mathrm{ZnO}(0001)$ single crystals at $300{ }^{\circ} \mathrm{C}$ under vacuum. The resulting Co-implanted $\mathrm{ZnO}$ single crystals and the subsequent $750{ }^{\circ} \mathrm{C}$ and $900{ }^{\circ} \mathrm{C}$ annealed samples are analysed with respect to their structural, optical, electronic, magnetic and ac electrical properties. Photoluminescence and $\mathrm{X}$-ray photoelectron spectroscopy results indicate the signatures of the $\mathrm{CO}^{2+}$ state and its substitution at the tetrahedrally coordinated $\mathrm{Zn}$-sites. $\mathrm{X}$-ray diffraction and $\mathrm{X}$-ray photoelectron spectroscopy identify the presence of the $\mathrm{ZnCO}_{2} \mathrm{O}_{4}$ and $\mathrm{Co}_{3} \mathrm{O}_{4}$ phases in the $900{ }^{\circ} \mathrm{C}$ annealed sample. By comparing the resistance response of the identified phases towards different magnetic environments, the impedance spectroscopy results successfully identify two magnetic phases $\left(\mathrm{ZnCO}_{2} \mathrm{O}_{4}\right.$ and $\left.\mathrm{CO}_{3} \mathrm{O}_{4}\right)$ and a paramagnetic $\left(\mathrm{CO}_{\mathrm{Zn}}\right)$ phase for the $750{ }^{\circ} \mathrm{C}$ and $900{ }^{\circ} \mathrm{C}$ annealed samples, implying the extrinsic nature of room temperature ferromagnetism. The observed ferromagnetism in each sample is not of single origin, instead the mutual effects of the secondary phases embedded in the paramagnetic host matrix are in competition with each other.

\section{Introduction}

The forecast of carrier assisted high temperature ferromagnetism in transition metal doped diluted magnetic semiconductors (especially in p-type $\mathrm{ZnO}^{1}$ ) has encouraged the scientific community to search for a realistic diluted magnetic semiconductor for practical applications. The $\mathrm{Co}-\mathrm{ZnO}$ material has been considered as a role model system for a wide range of diluted magnetic semiconductors after the $a b$ initio theoretical prediction of intrinsic ferromagnetism ${ }^{2}$ and the sequential experimental observation of room temperature ferromagnetism (RT FM) ${ }^{3}$ in this class of material. Regardless of this great prospective, understanding whether RT FM is intrinsic ${ }^{4,5}$ or related to clustering or incipient development of secondary phases, ${ }^{6,7}$ or totally absent, is still controversial. ${ }^{8,9}$ Furthermore, RT FM also depends on sample preparation and growth conditions and many experimental studies have identified that RT FM is absent in near-perfect epitaxial Co-doped $\mathrm{ZnO}$ films. ${ }^{10,11}$

\footnotetext{
${ }^{a}$ Department of Physics, The University of Hong Kong, Pokfulam Road, Hong Kong, P. R. China. E-mail: chuhan.pieas@gmail.com, ccling@hku.hk

${ }^{b}$ EMMG, Physics Division, PINSTECH, P.O. Nilore, Islamabad, Pakistan

${ }^{c}$ Department of Metallurgy and Materials Engineering, PIEAS, Nilore, Islamabad 45650, Pakistan

${ }^{d}$ Institute of Radiation Physics, Helmholtz-Zentrum Dresden-Rossendorf, Bautzner Landstr. 400, 01328 Dresden, Germany

${ }^{e}$ Department of Applied Physics, The Hong Kong Polytechnic University, Hong Kong, P. R. China

${ }^{f}$ Department of Physics, Hong Kong University of Science and Technology, Clear Water Bay, Kowloon, Hong Kong, P. R. China
}

In order to avoid problems associated with sample preparation, ion implantation is considered to increase sample preparation reproducibility and allows the precise control of the implanted ion concentration to overcome the solubility limit. ${ }^{12}$ Although a substantial amount of disorder will occur after ion implantation, ZnO exhibits a strong degree of dynamic annealing during ion bombardment (i.e. migration, interaction and recombination of ion-beam-generated intrinsic defects). Such an annealing process makes $\mathrm{ZnO}$ a radiation resilient material and it can bear high doses of irradiation without becoming amorphous. However, dynamic annealing is not $100 \%$ effective for full structural recovery of the lattice disorder. Dopant clusters and extended stacking faults may also accumulate during the ion bombardment process. ${ }^{13,14}$ Implantation at elevated temperatures may decrease the amount of disorder through the process of dynamic defect annealing and would also offer in situ thermal dopant activation. ${ }^{15}$

Our present study aims to investigate the different possible phases and their potential role in tuning the magnetic properties of high temperature $\left(300{ }^{\circ} \mathrm{C}\right)$ Co-implanted n-type $\mathrm{ZnO}$ single crystals. X-ray diffraction (XRD) and X-ray photoelectron spectroscopy (XPS) can reveal the crystalline and electronic structures of secondary phases, respectively, but they fail to offer any magnetism related information. Magnetic probes, like vibrating sample magnetometers (VSM) and superconducting quantum interference devices (SQUID), can detect the overall magnetism but are unable to distinguish between the intrinsic FM and the contribution of the multiple phases in the material under observation. 
Therefore, more local probe studies are needed to fairly separate the multiple phases if they are playing a role. Impedance spectroscopy (IS) is an informative and exceptional characterizing tool in fundamental and applied materials research. It can be used to resolve the contribution of the different phases to the electrical properties, such as the contact effects, grains, grain boundaries, and any type of impurity inside a sample. ${ }^{16,17}$ Compared to other techniques, IS explicitly distinguishes among the strongly coupled processes having different proceeding rates, ${ }^{18-20}$ as well as the concealed multiple phases having diverse conductivities even if the concentrations of the phases are very low. ${ }^{21,22}$ However, conventional IS does not offer any direct magnetic information on the individual phases.

In this research work, high quality single crystals have been used as the raw material to avoid the grain boundary defects. These defects have much higher relaxation times compared to grains and normally act as a potential source to activate the RT ferromagnetism by confining transition metals or impurities. ${ }^{16,23}$ Structural and electronic information of the phases were studied by XRD, XPS and photoluminescence (PL), and the magnetic properties were investigated by VSM. IS was used to separate the potential phases and to study their magnetic properties with the measurements done without the magnetic field (NMF), with the magnetic field (MF) and then after retreating from the magnetic field (AMF). The magnetic properties of the identified phases were obtained by comparing their component resistances measured under the different magnetic environments. The origins of the observed phases were suggested according to the comprehensive information obtained from the XRD, XPS, PL and IS measurements.

\section{Experimental}

The raw material used was the undoped melted grown $\mathrm{ZnO}(0001)$ single crystal obtained from Cermet Inc., USA. Its carrier concentration and mobility are $5 \times 10^{16} \mathrm{~cm}^{-3}$ and $\sim 203 \mathrm{~cm}^{2} \mathrm{~V}^{-1} \mathrm{~s}^{-1}$, respectively. Co ions with $100 \mathrm{keV}$ energy and a fluence of $10^{15} \mathrm{~cm}^{-2}$ were implanted into the $\mathrm{ZnO}$ single crystal at $300{ }^{\circ} \mathrm{C}$ under vacuum. Secondary ion mass spectroscopic (SIMS) measurements carried out by Cameca (Model IMS 4F) yielded a Co depth profile extending to a depth of $200 \mathrm{~nm}$ and an intensity that peaked at $50 \mathrm{~nm}$, which coincides well with Monte Carlo TRIM calculations. ${ }^{24}$ This corresponds to an average Co-doping concentration of $10^{19} \mathrm{~cm}^{-3}$ in the top $200 \mathrm{~nm}$ of depth. To further remove the ion-induced defects, post-implantation annealing is performed at $750{ }^{\circ} \mathrm{C}$ and $900{ }^{\circ} \mathrm{C}$ in $\mathrm{Ar}$ for 30 minutes. XRD was performed with a Bruker D8 Advance X-ray diffractometer using the $\mathrm{Cu} \mathrm{K} \alpha$ line $(0.1541 \mathrm{~nm})$. PL measurements were performed with the $325 \mathrm{~nm}$ He-Cd laser line with samples mounted in a $10 \mathrm{~K}$ closed cycled He refrigerator. The grating monochromator employed has a focal length of $500 \mathrm{~mm}$. The photons are detected by a photomultiplier tube (PMT) with the signal processed by a lock-in amplifier. The electronic structures of Co were studied by XPS using the MgK $\alpha$ line (Kratos Axis Ultra DLS system). The $\mathrm{X}$-ray source and the $\mathrm{C} 1 \mathrm{~s}$ line were taken as the standard.
Magnetic measurements ( $M-H$ loop) were performed at room temperature using a Lakeshore Model 7300 series VSM. Room temperature IS measurements were performed within the frequency range of $1 \mathrm{~Hz} \leq f \leq 10^{7} \mathrm{~Hz}$ using an Alpha-N analyzer (Novocontrol, Germany). To perturb the system, a low ac signal of $0.2 \mathrm{~V}$ was used. Fully automated WINDETA software was used for interfacing the experimental setup of the analyzer to the computer and for data acquisition. ZView (Complex Nonlinear Least Squares Immittance Data Fitting Program, Version 6.1-4/03/94) software was used for fitting and analyzing the measured impedance results within 1-2\% fitting error. The IS measurements were carried out under null magnetic field (NMF), with a constant magnetic field of $0.3 \mathrm{~T}$ perpendicular to the sample surface (MF), and 10 minutes after retreating from the magnetic field (AMF).

\section{Results and discussions}

\subsection{Structural and electronic properties}

The XRD patterns of Co-implanted ZnO samples (Fig. 1(a)) are dominated by the (002) peaks, which correspond to the $c$-axis orientated wurtzite $\mathrm{ZnO}$ structure. In comparison with pure ZnO single crystals, the intensity of the (002) peaks decreases for the Co-implanted samples, indicating the implantationinduced structural changes in the samples. The two new peaks are unambiguously observed in the slow scan XRD $\left(30.5^{\circ}\right.$ to $\left.32^{\circ}\right)$ of the $900{ }^{\circ} \mathrm{C}$ annealed sample (ann900) as shown in Fig. 1(b). The typical (100) reflection of $\mathrm{ZnO}$ normally exists around $31.8^{\circ}$ $\left(\sim 32^{\circ}\right)^{25,26}$ which is close to the newly observed peak positions in our ann900 sample. Therefore, in order to rule out the possibility of the (100) $\mathrm{ZnO}$ reflection due to the thermally induced reconstruction of ion-induced defects, the slow scan $\mathrm{XRD}$ for the $900{ }^{\circ} \mathrm{C}$ annealed $\mathrm{Cu}$-implanted $\mathrm{ZnO}$ single crystal prepared under the same conditions is also shown in Fig. 1(b). The lattice mismatch of the $\mathrm{Cu}^{2+}$ ion $(0.080 \mathrm{~nm})$ and $\mathrm{Zn}^{2+}$ ion $(0.083 \mathrm{~nm})$ is very small, and may result in a small lattice distortion when implanted into $\mathrm{ZnO} .{ }^{26}$ Within the detection limit of XRD, no peak around $31^{\circ}$ related to the (100) $\mathrm{ZnO}$ reflection is observed for the Cu-implanted $\mathrm{ZnO}$ single crystals annealed at $900{ }^{\circ} \mathrm{C}$ (Fig. 1(b)).

Thus, the observed new peaks for the Co-implanted samples (which are below the typical (100) ZnO reflection peak around $31.8^{\circ}$ ) and the absence of the (100) $\mathrm{ZnO}$ reflection in the $\mathrm{Cu}$-implanted $\mathrm{ZnO}$ single crystals suggest the presence of secondary phases in our $900{ }^{\circ} \mathrm{C}$ annealed Co-implanted samples. The two new peaks in the slow scan XRD (Fig. 1(b)) correspond to the spinel phases of $\mathrm{ZnCo}_{2} \mathrm{O}_{4}$ (JCPDS\# 021069) and $\mathrm{Co}_{3} \mathrm{O}_{4}$ (JCPDS\# 781970). Although the high temperature annealing of our ann900 sample successfully shows two secondary phases, we are unable to separate all the potentials phases for the $750{ }^{\circ} \mathrm{C}$ annealed sample (ann750) and the broad XRD peak at $31.20^{\circ}$ is interpreted as the superposition of the corresponding thermally induced evolving phases. These evolving phases are effectively well separated on the basis of their response towards IS (will be discussed in Section 3.3). Within the detection limit of XRD, signatures related to the Co cluster and $\mathrm{CoO}$ are not identified. Our SIMS results (not shown here) illustrate that in the as-implanted 

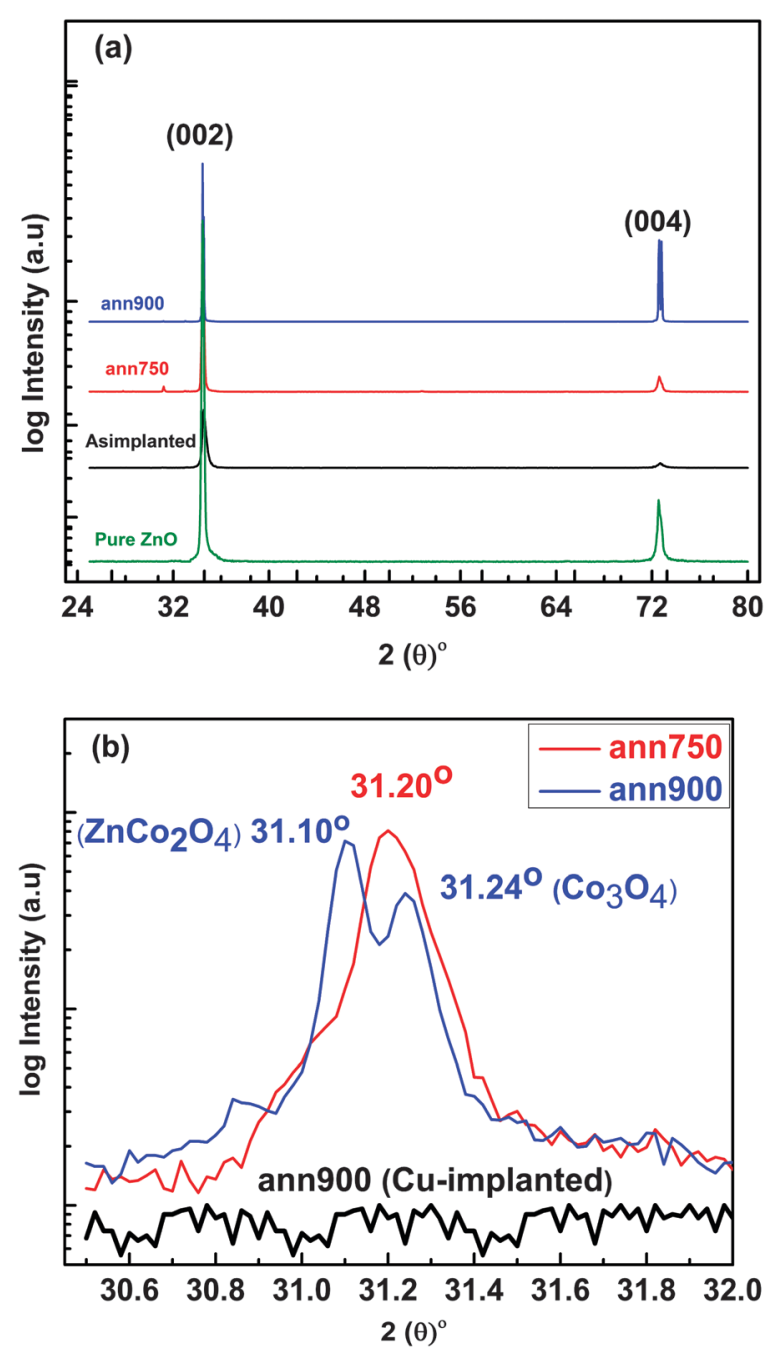

Fig. 1 (a) XRD patterns for the Co-implanted $\mathrm{ZnO}$ single crystal samples and the (b) slow scan XRD from $30.5^{\circ}$ to $32^{\circ}$ for the as-Co-implanted sample, the $750{ }^{\circ} \mathrm{C}$ and $900{ }^{\circ} \mathrm{C}$ annealed $\mathrm{Cu}$-implanted $\mathrm{ZnO}$ single crystals.

sample, Co ions are unevenly distributed to a depth of $\sim 200 \mathrm{~nm}$ from the surface with an average concentration of $\sim 0.60 \%$, and this distribution profile remains unaffected even after annealing at high temperatures $\left(900{ }^{\circ} \mathrm{C}\right)$.

In order to study the electronic structure of the substituted Co at the $\mathrm{Zn}$ site and the influence of the possible defects, PL measurements were performed at $10 \mathrm{~K}$ for the as-Co-implanted ZnO single crystal and the post-implantation annealed samples. The dominant peak around $3.35 \mathrm{eV}$ for both the un-implanted (inset of Fig. 2(a)) and the Co-implanted single crystals is related to the excitons bound to the neutral donors. ${ }^{27}$ After annealing the Co-implanted sample at $900{ }^{\circ} \mathrm{C}$, the intensity of this band edge emission decreases, showing the introduction of annealing induced defects in this sample. PL spectra of the ann750 and ann900 samples show broad green luminescence at $2.40 \mathrm{eV}$ in the visible region and it increases considerably for the ann900 sample. The origin of the green luminescence is still controversial and is attributed to $\mathrm{V}_{\mathrm{O}}, \mathrm{V}_{\mathrm{Zn}}$ and a $\mathrm{Cu}$ impurity. ${ }^{28,29}$ To get a deeper insight into the annealing induced green luminescence, we
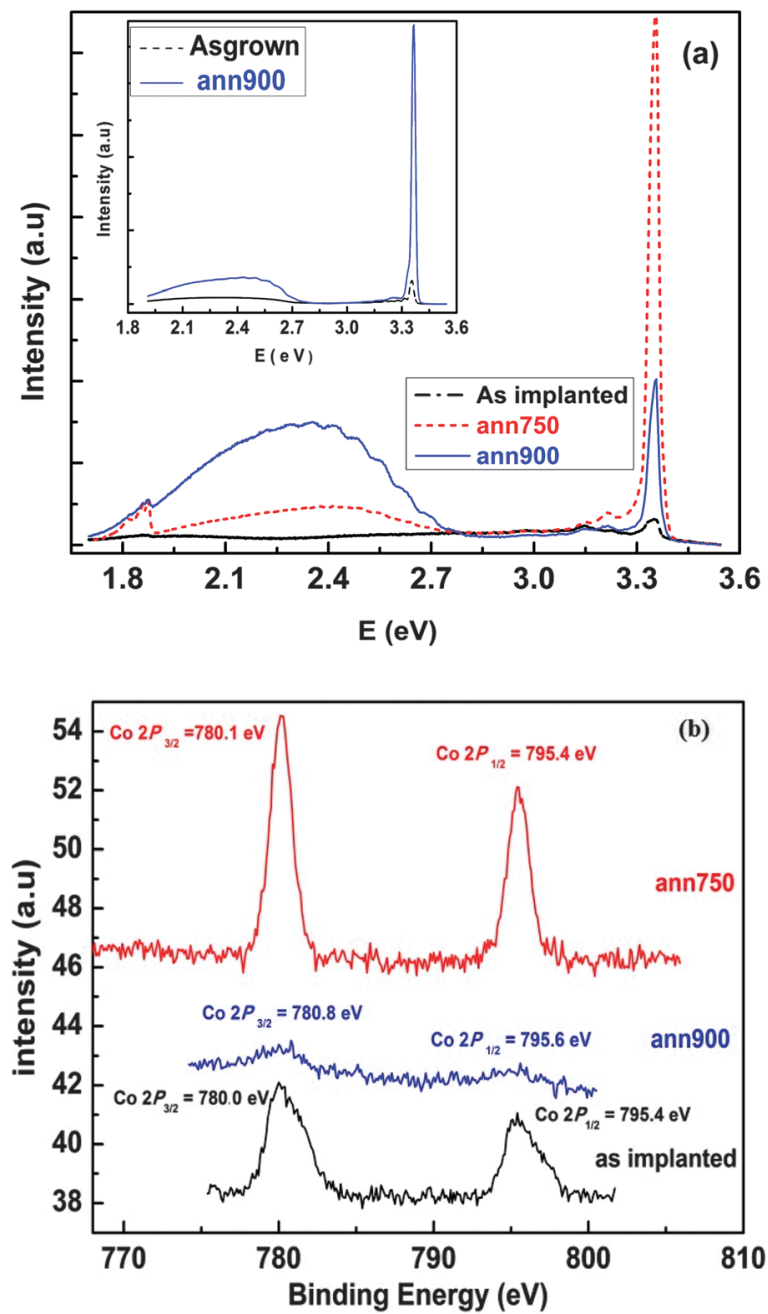

Fig. 2 (a) PL spectra for the Co-implanted samples at $10 \mathrm{~K}$. Inset shows the PL spectra for the un-implanted samples. (b) Room temperature XPS spectra of the Co $2 \mathrm{p}$ peaks in the Co-implanted samples.

compared the PL spectra of the implanted samples with the un-implanted pure ZnO single crystals (inset of Fig. 2(a)). The green luminescence was also found in both the as-grown pure $\mathrm{ZnO}$ single crystals and the $900{ }^{\circ} \mathrm{C}$ annealed Co-implanted sample. Furthermore, our pure $\mathrm{ZnO}$ thin films annealed at $750{ }^{\circ} \mathrm{C}$ and $900{ }^{\circ} \mathrm{C}$ grown by pulsed laser deposition technique show a similar green luminescence pattern (not shown here). Our observation regarding the green luminescence for single crystals and thin films suggests that the observed green luminescence is irrelevant to Co but rather an intrinsic property of single crystal and thin films. The additional peak at $1.884 \mathrm{eV}$ in the implanted samples is related to the electronic transitions between the d-levels of the isolated $\mathrm{Co}^{2+}$ ions in a tetrahedral symmetry of oxygen atoms which shows the Co substitution at the $\mathrm{Zn}$ site $\left(\mathrm{Co}_{\mathrm{Zn}}\right) .^{30,31}$

XPS has been employed to study the chemical state of Co ions in implanted samples. Fig. 2(b) shows the XPS Co 2p core level spectra. The positions and the Full Width at Half Maximum (FWHM) of peaks are presented in Table 1. For the as-implanted sample, the Co $2 \mathrm{p}_{3 / 2}$ peak $(780.0 \mathrm{eV})$ accompanied by the Co $2 \mathrm{p}_{1 / 2}$ peak $(795.4 \mathrm{eV})$ with $\Delta E=15.4 \pm 0.1 \mathrm{eV}$ indicates the existence of $\mathrm{Co}^{2+} \cdot{ }^{2,33}$ 
Table 1 Peak positions and FWHMs of the Co $2 p_{3 / 2}$ and Co $2 p_{1 / 2}$ peaks in the XPS spectra for the Co-implanted samples

\begin{tabular}{|c|c|c|c|c|c|}
\hline & Co $2 \mathrm{p}_{3 / 2}(\mathrm{eV})$ & FWHM & Co $2 \mathrm{p}_{1 / 2}(\mathrm{eV})$ & FWHM & $\Delta E(\mathrm{eV})$ \\
\hline As-implanted & $780.0 \pm 0.07$ & 2.14 & $795.4 \pm 0.03$ & 2.32 & $15.4 \pm 0.10$ \\
\hline ann750 & $780.1 \pm 0.04$ & 1.37 & $795.4 \pm 0.01$ & 1.45 & $15.3 \pm 0.03$ \\
\hline ann900 & $780.8 \pm 0.15$ & 6.68 & $795.6 \pm 0.17$ & 8.67 & $14.8 \pm 0.16$ \\
\hline
\end{tabular}

Although the XPS spectra show no detectable traces of $\mathrm{CoO}$ and Co clusters within the detection limit of XPS, the possible existence of $\mathrm{CoO}$ traces cannot be ignored completely due to the existence of $\mathrm{Co}^{2+}$. For the ann750 sample, the positions of the Co2 $\mathrm{p}_{3 / 2}$, Co $2 \mathrm{p}_{1 / 2}$ peaks and the $\Delta E=15.3 \pm 0.03 \mathrm{eV}$ are almost the same as that of the as-implanted sample. However, the Co peak intensities of the ann750 sample is much higher, indicating a more isolated character of the $\mathrm{Co}^{2+}$ ions. In the ann900 sample, the $\Delta E(=14.80 \pm 0.16 \mathrm{eV})$ is smaller than that of the as implanted and the ann750 samples. This could be due to the simultaneous existence of $\mathrm{Co}_{3} \mathrm{O}_{4}{ }^{32}$ and $\mathrm{ZnCo}_{2} \mathrm{O}_{4}$ phases in the ann900 sample, as revealed by the XRD result. The observed main Co $2 \mathrm{p}$ peak position in the ann900 sample also has a much broader FWHM ( $\sim 9 \mathrm{eV}$ ), plausibly implying the co-existence of the $\mathrm{Co}^{2+}$ and $\mathrm{Co}^{3+}$ states in these $\mathrm{Co}_{3} \mathrm{O}_{4}$ and $\mathrm{ZnCo}_{2} \mathrm{O}_{4}$ phases. In these spinel type phases, photoelectron signals from different oxygen coordination with the $\mathrm{Co}^{2+}$ and $\mathrm{Co}^{3+}$ states are intermingled and these are normally indistinguishable by XPS. ${ }^{34}$ Furthermore, Hays et al. ${ }^{33}$ and Petitto et al..$^{35}$ reported that in $\mathrm{Co}_{3} \mathrm{O}_{4}$ spinel type phase, the $\mathrm{Co}^{2+}$ and $\mathrm{Co}^{3+}$ oxidation states are thermodynamically stable and inter-convertible at the crystal surface, but under ambient conditions $\mathrm{Co}_{3} \mathrm{O}_{4}$ is the most stable phase.

\subsection{Magnetic properties}

The room temperature $M-H$ curve in Fig. 3 shows that the as-grown $\mathrm{ZnO}$ single crystal exhibits no hysteresis. For the as-implanted, ann750 and ann900 samples, FM is clearly observed in the low

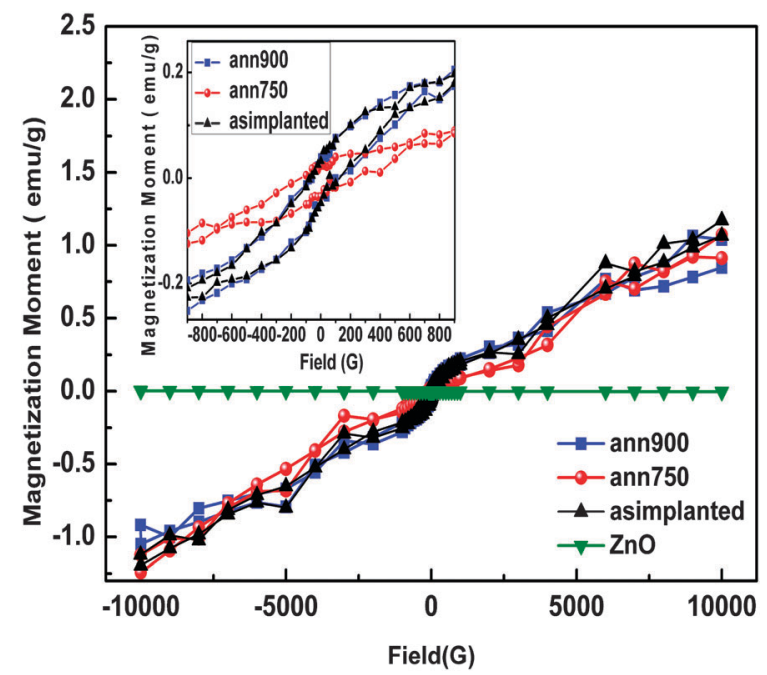

Fig. 3 Room temperature field vs. magnetization $(M-H)$ graph for the Co-implanted and the pure $\mathrm{ZnO}$ single crystals. Inset shows the magnetization in the low field region.
Table 2 Magnetic parameters for the Co-implanted $\mathrm{ZnO}$ single crystal annealed at different temperatures

\begin{tabular}{lllll}
\hline & $\mathrm{Mr}\left(\mathrm{emu} \mathrm{g}^{-1}\right)$ & $\mathrm{Ms}\left(\mathrm{emu} \mathrm{g}^{-1}\right)$ & $\mathrm{Hc}(\mathrm{G})$ & $\mu\left(\mu_{\mathrm{B}} / \mathrm{Co}\right)$ \\
\hline As-implanted & 0.05 & 0.19 & 151.16 & 0.478 \\
ann750 & 0.02 & 0.09 & 151.16 & 0.213 \\
ann900 & 0.04 & 0.19 & 110.00 & 0.463
\end{tabular}

field region (-800-800 G). Beyond this particular field, unsaturated magnetization trends at the higher field are correlated to the paramagnetic behaviour originating from the pronounced surface spin disorder. ${ }^{36}$ The observed magnetization is converted from emu units to $\mu_{\mathrm{B}} / \mathrm{Co}$ on the basis of the Co concentration obtained by SIMS measurement. The resultant magnetic parameters are tabulated in Table 2, indicating that the ann750 sample has lower values of remanence magnetization (Mr), saturation magnetization (Ms) and magnetic moment $\left(\mu_{\mathrm{B}} / \mathrm{Co}\right)$ compared to the ann900 sample. All the implanted samples show much smaller values of $\mu_{\mathrm{B}} / \mathrm{Co}\left(0.2-0.5 \mu_{\mathrm{B}} / \mathrm{Co}\right)$ than those of high-spin $\mathrm{Co}^{2+}\left(3 \mu_{\mathrm{B}} / \mathrm{Co}\right)$ and metallic Co $\left(1.73 \mu_{\mathrm{B}} / \mathrm{Co}\right) \cdot{ }^{37}$ The observed weak magnetic saturation not only shows the absence of metallic Co but also intimates that the ferromagnetic signal in these samples is mainly from the direct $\mathrm{Co}^{2+}-\mathrm{Co}^{2+}$ interactions. Furthermore, it is also observed that the intrinsic defects are not related to the magnetic properties of the implanted samples. Although the broad green luminescence peak in the as-grown pure $\mathrm{ZnO}$ single crystal (inset of Fig. 2a) indicates the existence of intrinsic defects, no FM is observed in this sample showing the irrelevance of the intrinsic defects to the magnetic properties. These observations show that weak FM in these samples is not of single origin, instead different behaviours are in competition with each other. To make a deeper analysis and explore the possible origin of the weak FM, IS under magnetic field was performed on these samples.

\subsection{Impedance spectroscopy}

In impedance measurements $Z^{\prime \prime}$ (the imaginary part of the impedance) $v s . Z^{\prime}$ (the real part of the impedance) plots generally appear in semicircular forms and the widths and heights of these semicircles are correlated with the resistive and capacitive behaviours of the material, respectively. Different surrounding environments of the existing multiple phases and defects within the materials under observation sometime generate more than one relaxation processes. Therefore, it is a common knowledge during impedance (i.e. $Z^{\prime \prime}$ vs. $Z^{\prime}$ plots) data analysis that it is hard to spread out the competing phases when the difference in relaxation times among phases is two orders of magnitudes or less. ${ }^{17,18}$ Different phases with approximately similar or comparable relaxation times for the involved carriers in conduction confer more depressed semicircular arcs.

The depressed semicircular arcs normally depict a smaller height than width, i.e. $Z_{\max }{ }^{\prime \prime}<1 / 2\left\{Z_{\max }{ }^{\prime}-Z_{\min }{ }^{\prime}\right\}$, where $Z_{\max }{ }^{\prime \prime}$ represents the vertical height of the semicircle and $Z_{\max }{ }^{\prime}$ and $Z_{\min }$ ' represent the real axis intercepts at the lower and higher frequency sides, respectively. The difference $Z_{\max }{ }^{\prime}-Z_{\min }{ }^{\prime}$ (diameter of the semicircle) provides the total resistance of the sample under consideration. ${ }^{17,18}$ Another more general observation 
in the impedance measurement is that sometimes the semicircular arc does not pass through the origin due to other arcs having higher relaxation frequencies beyond the measurement limit. ${ }^{17}$ In this situation we have to utilize other available formalisms for the better resolution of the competing relaxation processes.

3.3.1 Impedance plan plots $\left(Z^{\prime \prime}\right.$ vs. $\left.Z^{\prime}\right)$. Room temperature IS measurements were performed on the $750{ }^{\circ} \mathrm{C}$ and $900{ }^{\circ} \mathrm{C}$ post-implantation annealed samples. Fig. 4 shows the $Z^{\prime \prime}$ against $Z^{\prime}$ plots of the ann750 sample taken under the magnetic field. Ideally each of the phase components would generate a semi-circular arc in the $Z^{\prime \prime}-Z^{\prime}$ plot with its position dependent on the relaxation time $\tau=1 / \omega=R C$. At the maxima of the arc, the characteristic frequency is given by $\omega_{\max }=1 / R C .{ }^{19}$ One large arc and a small arc with horizontal axial lengths of $\sim 3.5 \mathrm{M} \Omega$ and $\sim 900 \Omega$ are respectively shown in Fig. 4 and its left inset.

For phases with very low resistance, only part of the corresponding arc can be seen in the $Z^{\prime \prime}-Z^{\prime}$ plot if the $\omega_{\max }$ is outside the available frequency range. ${ }^{20}$ In the right inset of Fig. 4, the non-zero intercept at the low $Z^{\prime}$ region (i.e. the high frequency) indicates the presence of an arc with $\omega_{\max }$ well above the maximum measurement frequency (i.e. $10^{7} \mathrm{~Hz}$ ). This implies that three phases are identified in the $Z^{\prime \prime}-Z^{\prime}$ plot of the ann750 sample measured with the magnetic field. A similar three-phase behaviour is found in the same sample after removal of the magnetic field.

In the $Z^{\prime \prime} v s . Z^{\prime}$ plots of the ann750 sample measured under the null magnetic field conditions as shown in Fig. 5 and that of the ann900 sample under the different magnetic environments (not shown here), two components are visually distinguished by the distorted arc and the non-zero intercept at high frequency.

Non-linear fitting was performed on all the $Z^{\prime \prime} v s . Z^{\prime}$ data using ZVIEW source code with the equivalent circuit model comprising of parallel $R$-CPE elements (associated with the

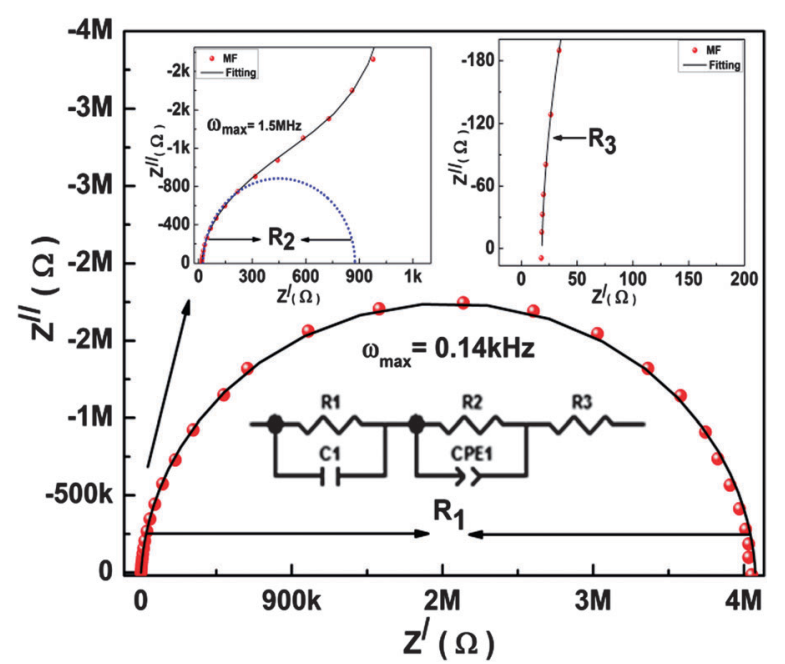

Fig. 4 Impedance plane plots for the ann750 sample under the magnetic field (MF). Frequency increases from right to left. The left and right insets are the enlarged views of the $Z^{\prime}=0-1 \mathrm{k} \Omega$ region and the $Z^{\prime}=0-200 \Omega$ region, respectively. The dots, solid lines, and dashed lines represent the data, the resultant fitted lines and the contributions from the individual elements, respectively. The fitted model is also included.

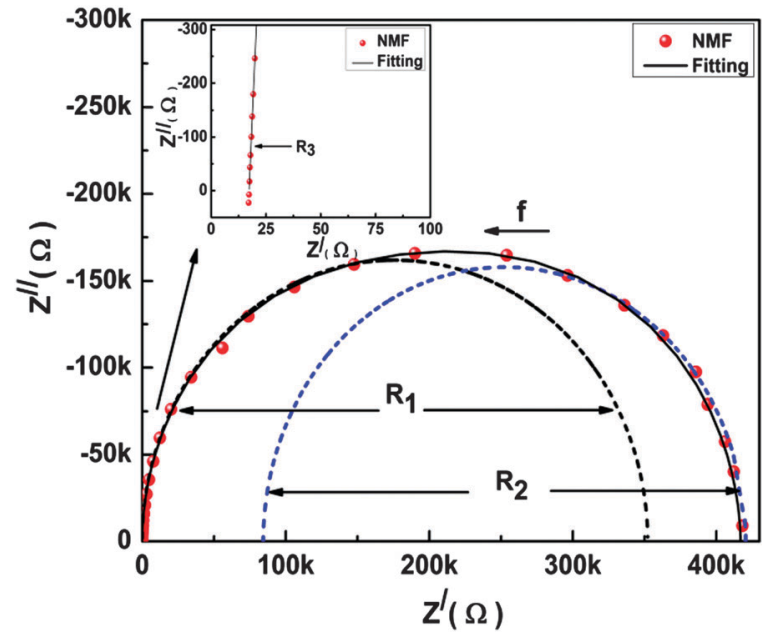

Fig. 5 Impedance plane plots for the ann750 sample under no magnetic field (NMF). Arrows show the increasing direction in frequency. The inset shows the enlarged view of the $Z^{\prime}(=0-100 \Omega$ ) region (i.e. high frequency region). The dots, solid lines, and dashed lines represent the data, resultant fitted lines and contributions from the individual elements, respectively.

corresponding phases) connected in series. The constant phase element CPE is given by:

$$
C=(\mathrm{CPE})^{1 / n} R^{(1-n) / n}
$$

The factor $n$ has the limiting cases $n=1$ and $n=0$ associated with the pure capacitive and pure resistive behaviours, respectively. ${ }^{18}$ Based on the chi-squares obtained from the trial fitting and the heterogeneity that is usually present in the post-ionimplantation annealed samples, CPE instead of capacitance is used in the equivalent circuit. This is also confirmed by the large depression angles as tabulated in Table 3. The depression angles for the ann750 and ann900 samples were estimated by fitting the impedance plane plot using ZVIEW software. We observe high values of the depression angle $\left(\sim 16^{\circ}\right)$ under no magnetic field conditions for a single semicircle of the ann750 sample. This high depression angle indicates the presence of inhomogeneity due to the existence of the intermingled multiple phases. The value of the depression angle falls to $\sim 9^{\circ}$ for small semicircles and $\sim 6-8^{\circ}$ for large semicircles for the same samples in the magnetic field and the null magnetic field conditions, respectively. This indicates improved phase stability with the application of the magnetic field; this explains the observation of the three clear phases in the impedance plan plots of this sample. For the ann900 sample we observe a high depression angle $\left(\sim 13^{\circ}\right)$ indicating again the presence of diverse phases with very close relaxation times.

The $Z^{\prime \prime}-Z^{\prime}$ plots were firstly fitted with the three-component model (i.e. the $\left(R_{1} \mathrm{CPE}_{1}\right)\left(R_{2} \mathrm{CPE}_{2}\right)\left(R_{3} \mathrm{CPE}_{3}\right)$ model), although in some of the $Z^{\prime \prime}-Z^{\prime}$ plots only two phases could be clearly visually separable. Processes with relaxation times differing less than two orders of magnitude cannot be clearly visually separable in the $Z^{\prime \prime}-Z^{\prime}$ plot. $^{17,18}$ We have also attempted to use the twocomponent model on those $Z^{\prime \prime}-Z^{\prime}$ plots which only showed two clearly distinguishable arcs, but we found that the chi-squares 
Table 3 The fitted parameters for the ann750 and ann900 samples of the Co-implanted ZnO single crystal in different environments

\begin{tabular}{|c|c|c|c|c|c|c|}
\hline & \multicolumn{3}{|l|}{ ann750 } & \multicolumn{3}{|l|}{ ann900 } \\
\hline$R_{1}(\Omega)$ & $2.31 \times 10^{5}$ & $3.71 \times 10^{6}$ & $2.21 \times 10^{5}$ & $1.53 \times 10^{5}$ & $3.24 \times 10^{3}$ & $2.41 \times 10^{3}$ \\
\hline$R_{2}(\Omega)$ & $1.3 \times 10^{5}$ & 980.1 & $2.01 \times 10^{3}$ & $4.6 \times 10^{5}$ & 621.3 & $8.71 \times 10^{3}$ \\
\hline $\mathrm{CPE}_{2}$ & $6 \times 10^{-10}$ & $2.1 \times 10^{-9}$ & $1.9 \times 10^{-9}$ & $1.2 \times 10^{-9}$ & $8 \times 10^{-10}$ & $9.4 \times 10^{-10}$ \\
\hline$n_{2}$ & 0.99 & 0.97 & 0.98 & 0.98 & 0.99 & 0.98 \\
\hline D.A. ${ }^{a}$ & 16.20 & $9.36^{\mathrm{C} 1}$ & $9.45^{\mathrm{C} 1}$ & 5.93 & 13.35 & 13.56 \\
\hline & & $6.18^{\mathrm{C} 2}$ & $8.024^{\mathrm{C} 2}$ & & & \\
\hline
\end{tabular}

${ }^{a}$ D.A. is depression angle, $\mathrm{C} 1=$ small semicircle at higher frequency, $\mathrm{C} 2=$ large semicircle at low frequency.

Table 4 The fitted resistances $R_{1}, R_{2}$ and $R_{3}$ of the $Z^{\prime \prime} v$ s. $Z^{\prime}$ plots for the Co-implanted $\mathrm{ZnO}$ single crystals annealed at $750{ }^{\circ} \mathrm{C}$ and $900{ }^{\circ} \mathrm{C}$ measured in different magnetic environments

\begin{tabular}{lllll}
\hline & $R_{1}\left(\mathrm{Co}_{3} \mathrm{O}_{4}\right)$ & $R_{2}\left(\mathrm{ZnCo}_{2} \mathrm{O}_{4}\right)$ & $R_{3}\left(\mathrm{Co}_{\mathrm{Zn}}\right)$ & $R_{\mathrm{t}}$ \\
\hline ann750 (NMF) & $2.31 \times 10^{5}$ & $1.3 \times 10^{5}$ & 18.28 & $3.6 \times 10^{5}$ \\
MF & $3.71 \times 10^{6}$ & 980.1 & 18.13 & $3.7 \times 10^{6}$ \\
AMF & $2.21 \times 10^{5}$ & $2.01 \times 10^{3}$ & 18.93 & $2.3 \times 10^{5}$ \\
ann900 (NMF) & $1.53 \times 10^{5}$ & $4.6 \times 10^{5}$ & 19.65 & $6.1 \times 10^{5}$ \\
MF & $3.24 \times 10^{3}$ & 621.3 & 34.47 & $3.9 \times 10^{3}$ \\
AMF & $2.41 \times 10^{3}$ & $8.71 \times 10^{3}$ & 23.61 & $1.1 \times 10^{4}$
\end{tabular}

were significantly inferior than those obtained by the threecomponent fitting. Our preliminary three-component fittings on all the samples and measuring magnetic environments have two findings, namely (1) all the fitted $n_{1}$ values are effectively close to unity showing a more capacitive behaviour of the associated phase, and (2) the third component is more conducting and showing a metallic type behaviour. We thus dropped capacitance from the third $R C$ component and carried out the final fittings using the $\left(R_{1} C_{1}\right)\left(R_{2} \mathrm{CPE}_{2}\right)\left(R_{3}\right)$ model. The best fitted results of all the parameters are tabulated in Table 3. The fitted resistances $R_{1}, R_{2}$ and $R_{3}$ are extracted and tabulated in Table 4 for further discussion.

It is worthy to discuss the physical origins of the three phases identified in the IS measurements. VSM and XRD data as presented previously showed that the Co-cluster and pure $\mathrm{Co}^{2+}$ (like CoO) phases were absent in the present samples and that only the $\mathrm{ZnCo}_{2} \mathrm{O}_{4}$ and $\mathrm{Co}_{3} \mathrm{O}_{4}$ phases are revealed by the XRD results. The Spinel type $\mathrm{ZnCo}_{2} \mathrm{O}_{4}$ has been reported to have high resistivity with hole/electron mediated ferromagnetic/ antiferromagnetic behaviors. ${ }^{38,39}$ The $\mathrm{Co}_{3} \mathrm{O}_{4}$ is conventionally regarded as paramagnetic with Neil temperature $T_{\mathrm{N}} \sim 30 \mathrm{~K}$ and has a normal spinel structure..$^{40,41}$

Regardless of the annealing temperatures and the measuring magnetic environment, $R_{3}$ is always as low as $\sim 15-30 \Omega$. This is attributed to the $\mathrm{Co}_{\mathrm{Zn}}$ site because of its metallic behaviour. The possibility of Co clustering is ruled out due to the low observed magnetic moments in the magnetization data. Park et al. ${ }^{42}$ also reported that Co clustering would occur in $\mathrm{Zn}_{1-x} \mathrm{Co}_{x} \mathrm{O}$ with $x>0.12$. Paramagnetic materials have a magnetic dipole moment owing to the incomplete cancellation of the electron spin or orbital magnetic moments. Without an external magnetic field, these moments are randomly oriented and thus resulting in a zero net magnetization. Under a magnetic field, these magnetic dipoles are individually aligned without any mutual interaction. ${ }^{43}$ During IS measurements in the null magnetic field and magnetic field conditions, we observe no appreciable change in $R_{3}$ in all the annealed samples. Even after retreating from the magnetic field (AMF), $R_{3}$ seems to possess its original value. The lacking response of the $R_{3}$ towards the magnetic environments shows that the phase is of metallic type with paramagnetic properties.

As shown in Table $4, R_{2}$ has a similar magnetic behaviour for both the $750{ }^{\circ} \mathrm{C}$ and $900{ }^{\circ} \mathrm{C}$ annealed samples. The $R_{2}$ value under no magnetic field conditions is $\sim 10^{5} \Omega$. It drops significantly to $\sim 1 \times 10^{3} \Omega$ under the magnetic field. It then slightly increases from $10^{3}$ to $10^{4} \Omega$ after the magnetic field is removed. In antiferromagnetic materials the spin moments of the neighbouring atoms or ions align in exactly the opposite directions. The solid as a whole thus retains no net magnetic moment. ${ }^{43}$ Dietl et al. ${ }^{44}$ reported that the ferromagnetic behaviour in Co-doped $\mathrm{ZnO}$ is due to the uncompensated spins at the surface of the antiferromagnetic Co-rich wurtzite ( $\mathrm{Zn}, \mathrm{Co}) \mathrm{O}$ phase distributed in the Co-poor (Zn, Co)O paramagnetic matrix. In our case, with the applied magnetic field, the uncompensated surface spins align accordingly. This reduces the carrier scattering and thus leads to a relatively lower impedance value. When the magnetic field is removed, these uncompensated surface spins stay aligned permanently but most of the bulk spins retain their original anti-parallel orientation and reintroduce the higher value of resistance to this phase. We thus attribute this phase to the $\mathrm{ZnCo}_{2} \mathrm{O}_{4}$ phase.

For the $750{ }^{\circ} \mathrm{C}$ annealed sample, the $R_{1}$ value under no magnetic field conditions is $\sim 10^{5} \Omega$. Under the applied magnetic field, it increases slightly to $\sim 10^{6} \Omega$, and then returns to $\sim 10^{5} \Omega$ after the magnetic field is removed. This observation is similar to a typical superparamagnetic behaviour. One of the plausible explanations is that $\mathrm{Ar}$ annealing relaxes the structure by freeing the adsorbed species on the phase boundary. This would allow the dangling bonds to support the frustrated spin disorder. Under the magnetic field, frustrated surface spins randomly oriented in a spin-glass-like structure would act as a trap for charge carriers, and thus create a higher resistance. ${ }^{45}$ After the removal of the magnetic field, 
this phase regains its original lower resistance. The exact origin of this superparamagnetic phase in the ann750 sample is not unambiguously known. In the ann750 samples, three component phases are competing, namely the $R_{1}\left(\mathrm{Co}_{3} \mathrm{O}_{4}\right)$ with superparamagnetic behaviour, the $R_{2}\left(\mathrm{ZnCo}_{2} \mathrm{O}_{4}\right)$ phase with a ferromagnetic surface and antiferromagnetic core, and finally the $R_{3}\left(\mathrm{Co}_{\mathrm{Zn}}\right)$ phase having a paramagnetic behaviour. The total resistance $\left(R_{\mathrm{t}}\right)$ of the ann750 sample shows the superparamagnetic type behavior which indicate an appreciable influence of the superparamagnetic $R_{1}\left(\mathrm{Co}_{3} \mathrm{O}_{4}\right)$ phase to the overall ferromagnetic behaviour; therefore we observed relatively lower values of $\mathrm{Mr}, \mathrm{Ms}, \mu_{\mathrm{B}} / \mathrm{Co}$ and a higher value of $\mathrm{Hc}$ for this sample as discussed previously.

For the ann900 sample, the response of $R_{1}$ towards the magnetic field is different. The $R_{1}$ value $\left(\sim 10^{5} \Omega\right)$ under no magnetic field decreases to $\sim 10^{3} \Omega$ when the measurements are taken under the magnetic field. It then maintains effectively the same value after the magnetic field is removed showing its ferromagnetic nature. The pure paramagnetic $\mathrm{Co}_{3} \mathrm{O}_{4}$ cannot account for this ferromagnetic behaviour, but the formation of a ferromagnetic region in the $\mathrm{Co}_{3} \mathrm{O}_{4}$ phase could offer a plausible explanation. Martin-Gonzalez et al. ${ }^{46}$ observed the surface reduction of the $\mathrm{Co}_{3} \mathrm{O}_{4}$ particle to ferromagnetic $\mathrm{CoO}$ in the $\mathrm{ZnO}-\mathrm{Co}_{3} \mathrm{O}_{4}$ mixture. A similar formation of a $\mathrm{CoO}$ ferromagnetic region has likely occurred on the surface of the $\mathrm{Co}_{3} \mathrm{O}_{4}$ phase. The superparamagnetic $R_{1}$ phase observed in the $750{ }^{\circ} \mathrm{C}$ sample as discussed in the last paragraph could be the intermediate phase for this ferromagnetic phase formed at $900{ }^{\circ} \mathrm{C}$ annealing. This is compatible with the XRD observation in which the $\mathrm{Co}_{3} \mathrm{O}_{4}$ peaks remained merged in a broad peak after $750{ }^{\circ} \mathrm{C}$ annealing but it is only clearly separable after $900{ }^{\circ} \mathrm{C}$ annealing (see Fig. 1(b)). The total resistance $\left(R_{\mathrm{t}}\right)$ of the ann900 sample shows a ferromagnetic type behaviour indicating the appreciable influence of the ferromagnetic $R_{1}\left(\mathrm{Co}_{3} \mathrm{O}_{4}\right)$ phase on the overall magnetic behaviour of this sample.

3.3.2 Modulus ( $M^{\prime \prime}$ vs. $\left.\log f\right)$ and $\operatorname{loss}\left(Z^{\prime \prime} v s . \log f\right)$ formalisms. Up to now we have discussed all the samples in the different environments using impedance plane plots and established the link among possible secondary phases and best fitted resistances. Impedance plane plots normally exploit the most resistive phase and the less resistive part is either suppressed or may stretch out the measuring range. The electrode and interface due to the space charge effects have high resistances. The high electrode resistance if present in the sample may overlap with the other high resistive phases, and can generate an ambiguous result. For the successful attachment of the fitted results to the observed phases, it is therefore necessary to rule out the possibility of the electrode effects. In the following section, both the loss and modulus formalisms will be discussed simultaneously to justify the existence of the secondary phases and the exclusion of the contact effect.

Complex impedance and complex modulus are the two general electrical parameters in the IS approach to differentiate the intermingled electronic process associated with a substantial mixture of highly conductive and highly resistive suspended phases. Complex impedance $\left(Z^{*}\right)$ and complex modulus $\left(M^{*}\right)$ can be calculated using the following relations of $Z^{*}=Z^{\prime}+j Z^{\prime \prime}$ and $M^{*}=M^{\prime}+j M^{\prime \prime}=j \omega C_{0} Z^{*}$, where $Z^{\prime \prime} / M^{\prime}$ and $Z^{\prime \prime} / M^{\prime \prime}$ are the real and imaginary parts of impedance and modulus, respectively, $\omega=2 \pi f$, is the angular frequency, $j^{2}=-1$ and $C_{0}$ is the empty cell capacitance. For a parallel $R C$ circuit, we have the following relations for $Z^{\prime}=R / 1+(\omega R C)^{2}, Z^{\prime \prime}=\omega C R^{2} /\left[1+(\omega C R)^{2}\right]$ and $M^{\prime}=$ $\omega^{2} R C C_{0} /\left[1+(\omega C R)^{2}\right], M^{\prime \prime}=\omega R C_{0} /\left[1+(\omega C R)^{2}\right] \cdot{ }^{17,18}$ The loss spectrum $\left(Z^{\prime \prime} v s . \log (f)\right)$ in the impedance formalism reveals the most resistive part of the material as $Z^{\prime \prime} \sim C R^{2}$, where $R$ and $C$ represent the resistance and capacitance of the associated phase. Modulus formalism $\left(M^{\prime \prime} v s\right.$. $\left.\log (f)\right)$ highlights the bulk properties of the material under consideration by suppressing the electrode/ interfacial polarization effects due to their large capacitance as $M^{\prime \prime} \sim 1 / C^{2} R^{2}$. In this approach, plot of $M^{\prime \prime} v s . \log f$ demonstrates a maximum at a characteristic frequency in the conduction process of the relevant phase. ${ }^{4-49}$

For the ann750 sample, we observed a noticeable impedance behaviour as shown in Fig. 6. In the absence of the magnetic field, only one distorted and asymmetric peak in both the loss and modulus spectra is observed. This broad distorted peak is correlated to the competing effects of the $\mathrm{ZnCo}_{2} \mathrm{O}_{4}$ and $\mathrm{Co}_{3} \mathrm{O}_{4}$ phases having comparable resistances (in consonance with the XRD result where superposition of two competing phases is interpreted as a single peak). However, the application of the magnetic field introduces the secondary phases by transforming the single peak into two different peaks (inset of Fig. 6). The loss spectrum shows only one peak related to the most resistive, i.e. the $\mathrm{Co}_{3} \mathrm{O}_{4}$ phase in this case. On the other hand, two well resolved peaks appear in the modulus formalism under the magnetic field and after the removal of the magnetic field. The lower and higher frequency peaks are coupled with the relaxation of dipoles in the low and the high conductivity $\mathrm{Co}_{3} \mathrm{O}_{4}$ and $\mathrm{ZnCo}_{2} \mathrm{O}_{4}$ phases, respectively. The low conductivity $\mathrm{Co}_{3} \mathrm{O}_{4}$ peaks at $\sim 20 \mathrm{~Hz}(\mathrm{MF})$ and $\sim 700 \mathrm{~Hz}$ (AMF) appear, respectively, in both the $M^{\prime \prime} v s . \log f$ and $Z^{\prime \prime} v s . \log f$ plots (inset of Fig. 6.), implying that there are no electrode and interfacial effects.

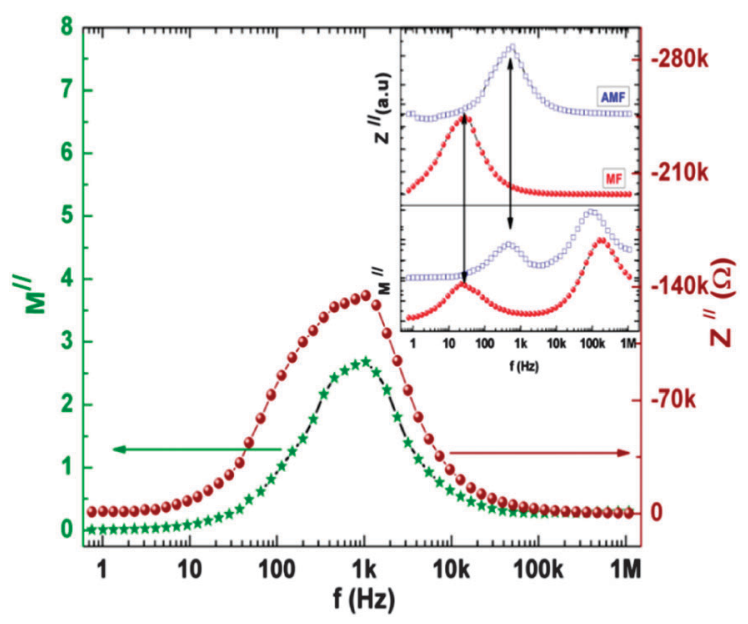

Fig. 6 The $M^{\prime \prime}$ vs. $\log (f)$ and $Z^{\prime \prime}$ vs. $\log (f)$ plots for the ann750 sample measured in the null magnetic field condition (NMF). The inserts show the $M^{\prime \prime}$ vs. $\log (f)$ and $Z^{\prime \prime}$ vs. $\log (f)$ plots measured within the magnetic field (MF) and after the removal from the magnetic field (AMF) for the same sample. 
It is because of the fact that the electrode/interfacial effects if present would appear as the most dominant peak in the loss spectrum $\left(Z^{\prime \prime} v s . \log f\right)$ due to their high resistance.

By comparing these findings with previous studies carried out by Wikberg et al..$^{50}$ and Ney et al. ${ }^{51}$ on Co-implanted ZnO single crystals, we successfully identified two spinel type secondary phases embedded in the $\mathrm{ZnO}$ host matrix by combining the impedance results with the other spectroscopic techniques. In both these studies, the Co ions (100 keV energy) were implanted into $\mathrm{ZnO}$ single crystals at room temperature with higher flux values and lower annealing temperatures compared to our case. No spinel type secondary phase was observed in the XRD pattern of the as-implanted and annealed samples, instead $\mathrm{a} \mathrm{Co}_{2} \mathrm{Zn}$ alloy was observed. ${ }^{50}$ However it was argued that for the consistent explanation of the observed ferromagnetic behaviour at least one ferromagnetic (ferrimagnetic) component with transition temperature closer to room temperature is still required. ${ }^{50}$ One of the possible reasons for their complete failure in filtering out all the potential phases inside the sample is related to the low annealing temperatures of $800{ }^{\circ} \mathrm{C}^{50}$ and $450{ }^{\circ} \mathrm{C} .{ }^{51}$ At these low annealing temperatures, thermally induced phases may be superimposed and remain undetected by XRD, similarly to our case for the ann750 sample, but these phases were effectively well separated by IS. The other possibility is the utilization of the high implantation dose in the above-discussed studies. At comparatively low defect concentrations, the efficiency of the $\mathrm{ZnO}$ surface on dynamic annealing may be higher leading to the more relaxed surface. The free $\mathrm{ZnO}$ surface acting as a defect sink at low fluence (similar to our case with fluence $\sim 1 \times 10^{15} \mathrm{~cm}^{-2}$ ) provides support to the dopant ions to find enough time and energy to settle down to form the spinel type secondary phases. On the other hand, at higher fluence, the defect sink properties of the surface might be degraded or dominated by the high defect concentration, leading to a more uniformly damaged surface. ${ }^{15,52}$ The damaged surface with higher fluence $\left(\sim 5 \times 10^{16} \mathrm{~cm}^{-2}\right.$ in the above discussed study ${ }^{50}$ ) might provide high energy to the dopant ions to form $\mathrm{Co}_{2} \mathrm{Zn}$ alloy along with the formation of other small size secondary phases that remain unnoticed by XRD due to the detection limit problem.

\section{Conclusions}

We have studied the secondary phases in Co-implanted ZnO using a comprehensive spectroscopic approach. PL and XPS results indicate the signature of the $\mathrm{Co}^{2+}$ state and its substitution at tetrahedrally coordinated $\mathrm{Zn}$-sites. XRD patterns for the ann900 sample reveal the $\mathrm{ZnCo}_{2} \mathrm{O}_{4}$ and $\mathrm{Co}_{3} \mathrm{O}_{4}$ phases after heat treatment. The impedance data are fitted with the three components $\left(R_{1} C_{1}\right)\left(R_{2} \mathrm{CPE}_{2}\right)\left(R_{3}\right)$ model within the null magnetic field, under magnetic field and after removal of the magnetic field environments for the ann750 and ann900 samples. IS results successfully differentiated the magnetic $\mathrm{ZnCo}_{2} \mathrm{O}_{4}$ and $\mathrm{Co}_{3} \mathrm{O}_{4}$ secondary phases in the Co-implanted $\mathrm{ZnO}$ as well as the paramagnetic $\mathrm{Co}_{\mathrm{Zn}}$ phase. The coinciding of the observed relaxation frequencies of both the loss and modulus spectra eliminate electrode interferences and show the real picture of the material. The observed FM in each sample is not of single origin but instead it is the joint effect of the secondary phases embedded in the paramagnetic host matrix. We suggest that the secondary phases are present all the time in the annealed samples but their thermal stability and mix relaxation frequencies limits their resolution. Although, the Co concentration is low in our samples, we have shown that impedance spectroscopy measurements under a magnetic field is a powerful tool to deliberately identify the intermingled phases when they are present with different conductivities.

\section{Acknowledgements}

The work presented here was supported by the RGC, HKSAR under the GRF (HKU703612P) and SEG_HKUST03, as well as HKU Seed Funding Program for Basic Research (201111159037), and the National Natural Science Foundation of China (No. 61205037). We are also thankful to the EMMG, PINSTECH, Nilore, Islamabad, Pakistan for providing the IS facilities.

\section{Notes and references}

1 T. Dietl, H. Ohno, F. Matsukura, J. Cibert and D. Ferrand, Science, 2000, 287, 1019.

2 K. Sato and H. Katayama-Yoshida, Jpn. J. Appl. Phys., 2000, 39, L555.

3 K. Ueda, H. Tabata and T. Kawai, Appl. Phys. Lett., 2001, 79, 988.

4 C. D. Pemmaraju, R. Hanafin, T. Archer, H. B. Braun and S. Sanvito, Phys. Rev. B: Condens. Matter Mater. Phys., 2008, 78, 054428.

5 G. Ciatto, A. Di Trolio, E. Fonda, P. Alippi, A. M. Testa and A. A. Bonapasta, Phys. Rev. Lett., 2011, 107, 127206.

6 S. Yin, M. X. Xu, L. Yang, J. F. Liu, H. Rösner, H. Hahn, H. Gleiter, D. Schild, S. Doyle, T. Liu, T. D. Hu, E. TakayamaMuromachi and J. Z. Jiang, Phys. Rev. B: Condens. Matter Mater. Phys., 2006, 73, 224408.

7 T. C. Kaspar, T. Droubay, S. M. Heald, M. H. Engelhard, P. Nachimuthu and S. A. Chamber, Phys. Rev. B: Condens. Matter Mater. Phys., 2008, 77, 201303(R).

8 C. N. R. Rao and F. L. Deepak, J. Mater. Chem., 2005, 15, 573.

9 Z. Jin, T. Fukumura, M. Kawasaki, K. Ando, H. Saito, T. Sekiguchi, Y. Z. Yoo, M. Murakami, Y. Matsumoto, T. Hasegawa and H. Koinuma, Appl. Phys. Lett., 2001, 78, 3824. 10 A. Ney, T. Kammermeier, K. Ollefs, S. Ye, V. Ney, T. C. Kaspar, S. A. Chambers, F. Wilhelm and A. Rogalev, Phys. Rev. B: Condens. Matter Mater. Phys., 2010, 81, 054420.

11 A. Ney, M. Opel, T. C. Kaspar, V. Ney, S. Ye, K. Ollefs, T. Kammermeier, S. Bauer, K. W. Nielsen, S. T. B. Goennenwein, M. H. Engelhard, S. Zhou, K. Potzger, J. Simon, W. Mader, S. M. Heald, J. C. Cezar, F. Wilhelm, A. Rogalev, R. Gross and S. A. Chambers, New J. Phys., 2010, 12, 013020.

12 S. Zhou, K. Potzger, G. Talut, H. Reuther, J. von Borany, R. Grötzschel, W. Skorupa, M. Helm, J. Fassbender, 
N. Volbers, M. Lorenz and T. Herrmannsdorfer, J. Appl. Phys., 2008, 103, 023902.

13 S. O. Kucheyev, J. S. Williams, C. Jagadish, J. Zou, C. Evans, A. J. Nelson and A. V. Hamza, Phys. Rev. B: Condens. Matter, 2003, 67, 094115.

14 A. Yu. Azarov, A. Hallén, X. L. Du, P. Rauwel, A. Yu. Kuznetsov and B. G. Svensson, J. Appl. Phys., 2014, 115, 073512.

15 M. A. Myers, M. T. Myers, M. J. Genera, J. H. Lee, L. Shao and H. Wang, Appl. Phys. Lett., 2012, 101, 112101.

16 J. C. A. Huang and H. S. Hsu, Appl. Phys. Lett., 2005, 87, 132503.

17 J. R. Macdonald, Impedance Spectroscopy Emphasing Solid Materials and Systems, Wiley, New York, 1987.

18 E. Barsoukov and J. R. Macdonald, Impedance Spectroscopy Theory, Experiments and Applications, John Wiley, New Jersey, 2nd edn, 2005.

19 D. C. Sinclair and A. R. West, J. Appl. Phys., 1989, 66, 3850.

20 D. C. Sinclair, T. B. Adams, F. D. Morrison and A. R. West, Appl. Phys. Lett., 2002, 80, 2153.

21 P. B. Macedo, C. T. Maynihan and R. Bose, Phys. Chem. Glasses, 1972, 13, 171.

22 V. Rovenzano, L. P. Boesch, V. Volterra, C. T. Moynihan and P. B. Macedo, J. Am. Ceram. Soc., 1972, 55, 492.

23 H. S. Hsu, J. C. A. Huang, S. F. Chen and C. P. Liu, Appl. Phys. Lett., 2007, 90, 102506.

24 J. F. Ziegler, J. P. Biersack and U. Littmark, The Stopping and Range of Ions in Solids, Pergamon, New York, 1985.

25 X. Penga, J. Xub, H. Zanga, B. Wangb and Z. Wang, J. Lumin., 2008, 128, 297.

26 G. K. Mani and J. B. B. Rayappan, J. Alloys Compd., 2014, $582,414$.

27 P. A. Rodnyi and I. V. Khodyuk, Opt. Spectrosc., 2011, 111, 776.

28 E. Biegger, M. Fonin, U. Rüdiger, N. Janßen, M. Beyer, T. Thomay, R. Bratschitsch and Yu. S. Dedkov, J. Appl. Phys., 2007, 101, 073904.

29 H. S. Kang, J. S. Kang, J. W. Kim and S. Y. Lee, J. Appl. Phys., 2004, 95, 1246.

30 V. V. Strelchuk, V. P. Bryksa, K. A. Avramenko, P. M. Lytvyn, M. Ya. Valakh, V. O. Pashchenko, O. M. Bludov, C. Deparis, C. Morhain and P. Tronc, Semicond. Phys., Quantum Electron. Optoelectron., 2011, 14, 31.

31 J. W. Quilty, A. Shibata, J. Y. Son, K. Takubo, T. Mizokawa, H. Toyosaki, T. Fukumura and M. Kawasaki, Phys. Rev. Lett., 2006, 96, 027202.

32 J. F. Moulder, W. F. Stickle, P. E. Sobol and K. D. Bomben, Handbook of X-ray Photoelectron Spectroscopy, Perkin-Elmer, Eden Prairie, 1992.
33 J. Hays, K. M. Reddy, N. Y. Graces, M. H. Engelhard, V. Shutthanandan, M. Lue, C. Xu, N. C. Giles, C. Wang, S. Thevuthasan and A. Punnoose, J. Phys.: Condens. Matter, 2007, 19, 266203.

34 B. J. Tan, K. J. Klabunde and P. M. A. Sherwood, J. Am. Chem. Soc., 1991, 113, 855.

35 S. C. Petitto, E. M. Marsh, G. A. Carson and M. A. Langell, J. Mol. Catal. A: Chem., 2008, 281, 49.

36 M. Younas, M. Nadeem, M. Atif and R. Grossinger, J. Appl. Phys., 2011, 109, 093704.

37 M. Ivill, S. J. Pearton, S. Rawal, L. Leu, P. Sadik, R. Das, A. F. Hebard, M. Chisholm, J. D. Budai and D. P. Norton, New J. Phys., 2008, 10, 065002.

38 M. Dekkers, G. Rijnders and D. H. A. Blankb, Appl. Phys. Lett., 2007, 90, 021903.

39 H. J. Kim, I. C. Song, J. H. Sim, H. Kim, D. Kim, Y. E. Ihm and W. K. Choo, J. Appl. Phys., 2004, 95, 7387.

40 P. Dutta, M. S. Seehra, S. Thota and J. Kumar, J. Phys.: Condens. Matter, 2008, 20, 015218.

41 M. Hamdani, R. N. Singh and P. Chartier, Int. J. Electrochem. Sci., 2010, 5, 556.

42 J. H. Park, M. G. Kim, H. M. Jang, S. Ryul and Y. M. Kim, Appl. Phys. Lett., 2004, 84, 1338.

43 B. D. Cullity, Introduction to Magnetic Materials, AddisonWesley, Readings, Massachusetts, 2nd edn, 1978.

44 T. Dietl, T. Andrearczyk, A. Lipińska, M. Kiecana, M. Tay and Y. Wu, Phys. Rev. B: Condens. Matter Mater. Phys., 2007, 76, 155312.

45 M. Younas, M. Atif, M. Nadeem, M. Siddique, M. Idrees and R. Grossinger, J. Phys. D: Appl. Phys., 2011, 44, 345402.

46 M. S. Martin-Gonzalez, J. F. Fernandez, F. Rubio-Marcos, I. Lorite, J. L. Costa-Kramer, A. Quesada, M. A. Banares and J. L. G. Fierro, J. Appl. Phys., 2008, 103, 083905.

47 P. B. Macedo, C. T. Maynihan and R. Bose, Phys. Chem. Glasses, 1972, 13, 171.

48 V. Rovenzano, L. P. Boesch, V. Volterra, C. T. Moynihan and P. B. Macedo, J. Am. Ceram. Soc., 1972, 55, 492.

49 I. M. Hodge, K. L. Ngai and C. T. Moynihan, J. Non-Cryst. Solids, 2005, 351, 104.

50 J. M. Wikberg, R. Knut, A. Audren, M. Ottosson, M. K. Linnarsson, O. Karis, A. Hallén and P. Svedlindh, J. Appl. Phys., 2011, 109, 083918.

51 V. Ney, S. Ye, T. Kammermeier, A. Ney, H. Zhou, J. Fallert, H. Kalt, F. Y. Lo, A. Melnikov and A. D. Wieck, J. Appl. Phys., 2008, 104, 083904.

52 M. T. Myers, S. Charnvanichborikarn, L. Shao and S. O. Kucheyev, Scr. Mater., 2012, 67, 65. 